\title{
Lusioersily
}

\section{Climate and species richness patterns of freshwater fish in North America and Europe}

Griffiths, D., McGonigle, C., \& Quinn, R. (2014). Climate and species richness patterns of freshwater fish in North America and Europe. Journal of Biogeography, 41(3), 452-463. https://doi.org/10.1111/jbi.12216

Link to publication record in Ulster University Research Portal

\section{Published in:}

Journal of Biogeography

\section{Publication Status:}

Published (in print/issue): 11/02/2014

DOI:

10.1111/jbi.12216

\section{Document Version}

Author Accepted version

\section{General rights}

Copyright for the publications made accessible via Ulster University's Research Portal is retained by the author(s) and / or other copyright owners and it is a condition of accessing these publications that users recognise and abide by the legal requirements associated with these rights.

\section{Take down policy}

The Research Portal is Ulster University's institutional repository that provides access to Ulster's research outputs. Every effort has been made to ensure that content in the Research Portal does not infringe any person's rights, or applicable UK laws. If you discover content in the Research Portal that you believe breaches copyright or violates any law, please contact pure-support@ulster.ac.uk. 
1 Original article

2

3

Climate and species richness patterns of freshwater fish in North America and Europe

4

David Griffiths, Chris McGonigle, Rory Quinn

5

School of Environmental Sciences, University of Ulster

6

7 Address: David Griffiths, School of Environmental Sciences, University of Ulster, Cromore Road, Coleraine

8 BT52 1SA, UK

$9 \quad$ Email: $\underline{\text { d.griffiths@ulster.ac.uk }}$

10

11 Running head: Climatic effects on freshwater fish richness gradients

12

13 Abstract word count: 233

14 Total word count: 7254

15 Estimated Fig/Table pages: 2.5

16 
17 Aim To investigate the effect of climatic, historical and spatial variables on species richness patterns in freshwater fish in North America and Europe.

Methods Regional species lists were used to document the spatial richness patterns. Three realms, Europe and Pacific and Atlantic North America, were identified. The numbers of species, by habitat, migration and distributional range categories, were calculated and the contributions of regional mean and seasonal temperature and rainfall, historical (realm, glaciation), and spatial (area, elevational range) variables to predicting richness were assessed using boosted regression tree, model-average and spatially explicit models.

Results The latitudinal temperature gradient is stronger than that for rainfall in the Atlantic realm whereas the rainfall gradient in Europe is independent of the temperature gradient. Temperature has a greater effect than rainfall on species richness, and these effects are stronger in the Atlantic than in Europe. Climate, particularly maximum monthly temperature, is the best predictor of richness in rivers whereas climate variables are less important than historical/spatial variables in diadromous species.

Main conclusions Freshwater fish richness differences between the Atlantic and European realms follow differences in spatial climatic trends. The contributions of climatic, historical and spatial variables vary with ecology: temperature is a better predictor of richness than rainfall in river-dwellers. The richness gradient is driven more by physiological than by energetic constraints on species. The importance of history is probably underestimated because of correlations with climate variables.

Keywords: boosted regression trees, climatic variability hypothesis, historical effects, rainfall, physiological tolerance hypothesis, spatial gradients, species-energy hypothesis, temperature, 


\section{Introduction}

Many hypotheses have invoked climatic effects to explain latitudinal richness gradients (Willig et al., 2003). The species-energy hypothesis argues that food supply determines the number of species an area can support (Storch, 2012): for example, mean annual temperature and/or rainfall predict both terrestrial productivity and species richness (Hawkins et al., 2003a). The physiological tolerance hypothesis proposes that species limits are determined by climatic extremes, such as temperature and rainfall maxima and/or minima, and that environments become less tolerable towards the poles (Currie et al., 2004): species adapt to extreme environments by, for example, being generalists or migrating (Southwood, 1977). Seasonal and interannual climatic variability increases with latitude (Stevens, 1989; Ferguson \& Messier, 1996), favouring generalist, high vagility, large range species (Griffiths, 2010; Jocque et al., 2010) and, in the long term, fewer species, because climatic variation reduces speciation and increases extinction rates (Dynesius \& Jansson, 2000; Jocque et al., 2010). Space affects richness because larger areas support more habitats (habitat heterogeneity hypothesis) and because larger areas show increased speciation and reduced extinction over long time periods: the greater area of tropical biomes has been suggested as a reason for the richness gradient (Rosenzweig, 1995). Historical explanations note that richness might not be determined just by current climate but that past events such as glaciations reduce richness by increasing extinctions, while surviving species, which differ in dispersal ability (vagility), take time to respond to those events.

Analyses of many taxa, including freshwater fish, have shown that climate-energy, spatial and historical factors are important richness predictors (Field et al., 2009; Oberdorff et al., 2011; Tisseuil et al., 2012), with climate having the greatest effect. Smith et al. (2010) found significant effects of annual rainfall and of temperature extremes on fish richness in both the species-rich Atlantic and species-poor Pacific realms of North America i.e. east and west of the Continental Divide. Knouft \& Page (2011) demonstrated significant effects of temperature and rainfall variables on total and family richness of North American freshwater fish but with other, habitat, variables contributing. However in studies over a more limited latitudinal range, historical factors were more important than climate in accounting for regional variation in fish species composition in Iberia (Filipe et al., 2009), tropical Africa and South and Central America (Tedesco et al., 2005).

Strong correlations between climate and the latitudinal species richness gradient have been interpreted as evidence that contemporary processes are the main determinants of richness gradients (Hawkins et al., 2003a; Currie et al., 2004; Field et al., 2009), but historical climatic measures can be at least as important as contemporary ones (Svenning \& Skov, 2005; Tedesco et al., 2005; Willis et al., 2007; Araújo 
et al., 2008; Leprieur et al., 2011). Identifying environmental variables as ecological or spatial/historical is not straightforward. Elevational heterogeneity, glaciation and realm have all been treated as historical, and climatic variation as ecological, variables. However, current climates are correlated with past climates (Willis et al., 2007; Araújo et al., 2008), while elevational heterogeneity, a consequence of historical change, is also associated with small-scale climatic differences (Schuldt \& Assmann, 2009).

Mean annual temperature and rainfall predict terrestrial net primary productivity (NPP) (Lieth, 1975), which has been suggested to correlate with aquatic primary, and consequently secondary, productivity (Livingstone et al., 1982; Oberdorff et al., 1995). However, temperature and rainfall also have other effects on freshwater fish. Temperature extremes affect fish survival and richness by thermal and oxygen stress and by freezing (Matthews, 1998) while rainfall affects fish richness via stream hydrology. Mean annual discharge, which varies with rainfall (Gregory \& Walling, 1973; Jones, 1997) and is regarded as a measure of river habitat volume, correlates with species richness (Oberdorff et al., 1995; Xenopoulos et al., 2005). Poff \& Ward (1989) characterised flow regime variability by the degree of intermittency, by flood frequency and predictability, and by flow predictability and suggested that all were likely to influence species richness. Low flows can also reduce oxygen concentrations while high flows increase turbidity and the risk of wash-out. Consequently, correlations between mean annual, extreme and variability climatic measures and fish richness do not, by themselves, identify the driving factors.

In this paper we document gradients in mean, extremes and variability in temperature and rainfall in Europe and North America, explore how well these climatic variables correlate with richness gradients in their freshwater fish faunas and investigate the contribution of spatial and historical factors to these patterns. We examine the following hypotheses:

1) Species richness is determined mainly by temperature. Temperature has energy supply and/or physiological effects which affect all species but responses to rainfall factors will vary, for example with habitat.

2) Species with similar habitats, migration behaviours and/or distributional ranges should be similarly affected by climatic variables. Specifically, climate variable importance for total, for resident and for river species richness categories should be similar since the latitudinal richness gradient is largely determined by riverdwellers and most river species are resident (Griffiths, 2006; 2010), and for migratory and non-endemic species since both experience a wide range of environments. As migratory species are adapted to varying 
environments the variation in richness explained by climate should be less in migratory than in resident species.

3) Climate annual means, extremes and variability are all important in determining species richness. Annual means are correlated with energy/productivity (Clarke \& Gaston, 2006) while climatic extremes constrain richness by exceeding species fundamental niches (Gaston, 2003). Variability affects species richness by increasing extinction risk, favouring migration and consequently greater gene flow and reduced speciation (Mittelbach et al., 2007). Additionally, assemblages in more variable environments have proportionally fewer specialists (Vásquez \& Stevens, 2004). Consequently, regions exhibiting greater temporal variation should support fewer species.

4) Contemporary climate determines richness patterns and historical factors are not important. Realm differences in the importance of climatic effects on species richness should depend on the degree of spatial climatic variation. In addition, taxa differ in environmental requirements as a consequence of their evolutionary history and so faunas of differing origin and composition could be affected by different climatic variables (Knouft \& Page, 2011).

Alternatively, historical factors influence richness patterns and regional scale factors such as glaciation and/or aridity also contribute to richness gradients. Gradients in aquatic richness with elevation (for example Kratz et al., 1997; Fu et al., 2004) persist after accounting for climatic variables (Zhao et al., 2006; Smith et al., 2010; Knouft \& Page, 2011). Similarly, glaciation effects have been detected after accounting for climate/productivity variables (Oberdorff et al., 1999; Tedesco et al., 2005).

\section{Methods}

Data

There are large-scale faunal differences within North America (Moyle \& Herbold, 1987) and we use the term realm for those areas east and west of the Continental Divide in North America (Atlantic, Pacific) and for Europe. These were subdivided into regions based on faunal similarities (Griffiths, 2006; 2010): the Pacific realm included coastal regions up to and including the Yukon.

The 1910-1950 North American and European climate dataset (CRU TS 1.2) was obtained from the University of East Anglia Climatic Research Unit (http://www.cru.uea.ac.uk/). Climatic variables were extracted by E-clic (Tarroso \& Rebelo, 2010) and compiled into regional values in ArcGIS v9.3. Topographic data for the 
127 North American and European regions identified by Griffiths $(2006 ; 2010)$ were extracted from the Global 30 Arc-Second Elevation Data Set (GTOPO30).

A number of regional temperature $(T)$ and rainfall $(R)$ measures were calculated: annual means were used as indicators of energy/productivity, and extremes and temporal variation as physiological tolerance and climatic variability indicators (Clarke \& Gaston, 2006). All variables were averages over the 1910-1950 period, a time span chosen to precede the more recent, rapid, climatic changes. Regional annual climate means ( $T_{\text {mean, }} \mathrm{R}_{\text {mean }}$ ) are the averages over all $0.5^{\circ} \times 0.5^{\circ}$ grid squares comprising a region while spatial values (sp) are the standard deviations over these squares. Seasonal temporal variation (te) was estimated as the standard deviation of mean monthly values over nine adjacent grid squares, centred on the mean latitude and longitude for each region: any bias introduced by using this smaller number of grid squares is likely to be small since annual means estimated in this way are strongly correlated with annual means calculated over the whole region $(r=0.99,0.96$ for temperature and rainfall). Climate extremes $(\max , \min )$ were calculated as the largest and smallest mean monthly regional values while range is the difference between these extremes.

We used the regional species presence/absence lists analysed by Griffiths (2006; 2010). In most instances these regions are based on drainage basins, but the Mississippi and Danube basins were subdivided while some regions contain several basins. Regional/drainage basin rather than grid square richness was preferred because $92 \%$ of the species are restricted to freshwater and hence the catchment constitutes a biologically meaningful unit (Tedesco et al., 2005). The regional boundaries defined by the European Environment Agency (http://www.eea.europa.eu/data-and-maps/figures/ecoregions-for-rivers-andlakes) were used rather than those in Illies (1978). While some regional boundaries have changed from those constructed by Illies this has not affected the species lists. Following Griffiths (2006; 2010), species were classified by habitat (river or lake), migration category (diadromous, potamodromous or resident) and distributional range (endemic or non-endemic). Rivers and lakes contain habitat specialists (riverine, lacustrine species) and generalists, which occur in both habitats: endemics occur in only one region. Flowing water habitats were divided into five channel size classes, as headwater, creek, small, medium and large rivers (Page \& Burr, 1991) and these categories assigned scores of 1-5.

Elevational range, the difference between the highest and lowest points in a region, was used as a measure of spatial heterogeneity (Jetz \& Rahbek, 2002) as were $T_{s p}$ and $R_{s p}$ because they measure variation within a region. 
157 We grouped the variables as climatic (annual mean, maximum, minimum, temporal variation of temperature

158 and rainfall), historical (realm, glaciation) and spatial (area, elevational range, $T_{s p}, R_{s p}$ ). Their relative 159 influence as richness predictors was assessed by boosted regression trees (BRT), using the dismo package 160 (Hijmans et al., 2013) of R v2.15.2 (R Core Development Team, 2012). We assumed a Gaussian distribution 161 of the response variable. Optimal model parameters were determined by altering the number of trees and the 162 learning rate until predictive deviance was minimized without overfitting (Elith et al., 2008). To determine if 163 variation in regional area affected the results we calculated interaction terms between the predictor variables: none was significant. The relative contributions of predictor variables for each model were clustered across richness categories using Ward's method on Euclidean distance. Post-hoc tests, of the hypothesis Atlantic richness differs from that of the other realms, were conducted using the BRT partial dependence values (i.e. after adjusting for the average effects of the other variables) for each richness category.

To test for phylogenetic effects we examined the predictive contributions of annual mean and seasonality in temperature and rainfall to richness of species-rich families $(n \geq 8)$ in the Atlantic and European realms: the Pacific was omitted because of the small number of regions $(n=8)$. Because of the limited

172 the multi-model inference module in SAM v4.0 (Rangel et al., 2010). Predictors were standardised to zero 173 mean and unit standard deviation so the magnitudes of the regression coefficients are directly comparable:

174 the conclusions do not change when all climate variables were used.

The degree of spatial autocorrelation within realms was assessed by comparing correlograms for the 176 raw data and the residuals from climate models, using the simultaneous autoregressive (SAR) procedure in 177 SAM. This comparison allows assessment of how effectively the climate variables (all except sp) predict 178 regional spatial structure in species richness (Diniz-Filho et al., 2003). Collinearity amongst predictor variables can be a problem when using ecological variables, with a risk 180 of incorrect identification of the best model (Dormann et al., 2013). One potential solution, the creation of 181 independent variables using principal components analysis, did not help to distinguish between hypotheses 182 since the majority of the climate variables were correlated with the first component, making interpretation 183 difficult. Mean annual temperature and rainfall were strongly collinear with some of the other predictors $184(|r|>0.7$, see Appendix S1). Omitting these variables removed the collinearity but had very little effect on 185 relative influence values estimated by BRT ( $R^{2}$ across influence estimates varied between 0.96-1.00 for the 
various richness categories). Consequently, we report analyses using all predictors because removing climate means would not permit consideration of the species-energy hypothesis.

All nonlinear trend lines in the figures are fitted by locally weighted scatterplot smoothing (LOWESS). All richnesses are $\log _{10}(x+1)$ transformed.

\section{Results}

\section{Climate patterns}

The latitudinal gradients in temperature are more marked than those in rainfall (Fig. 1). These temperature gradients are steeper and longer in the Atlantic than in the Pacific or European realms (Fig. 1a, slopes $F_{1,43}=$ 25.64, $P<0.001 ; F_{1,59}=62.32, P<0.001$ respectively). While the numbers of significant correlations between temperature and between rainfall variables within each realm are similar (6-7/10, see Appendix S1) there are 21/25 (13 positive) significant correlations between temperature and rainfall variables in the Atlantic but only $4 / 25$ in Europe $(z=4.81, P<0.001)$ i.e. rainfall and temperature variables covary more frequently in the Atlantic realm.

In the Atlantic, $T_{\text {mean }}$ declines strongly with increasing latitude while longitude has no effect (standardised coefficients for latitude and longitude -0.98, -0.04) whereas $\mathrm{R}_{\text {mean }}$ latitudinal and longitudinal effects are of similar magnitude (standardised coefficients $-0.62,0.56$ respectively). Annual mean and extreme temperatures and rainfall decline with increasing latitude (Table 1a). Seasonal variation in temperature increases with latitude while rainfall seasonality decreases. In Europe, $T_{\text {mean }}$ also declines with increasing latitude, unlike $R_{\text {mean }}$ which declines to the east (standardised temperature coefficients for latitude and longitude $-0.87,0.27$; standardised rainfall coefficients $-0.08,-0.63)$. Temperature seasonality also increases eastwards but not with latitude i.e. it is orthogonal to $T_{\text {mean, }}$ while rainfall seasonality shows no spatial trends. . Europe shows significantly less seasonality than the Atlantic $\left(F_{1,61}=8.04,6.39, P<0.01\right.$ for $T_{\text {te }}$ and $R_{\text {te }}$ respectively). Over most latitudes, Europe has higher maximum and minimum temperatures and shows less temperature seasonality but there are no consistent realm differences in rainfall (see Appendix S1).

The climate variables are correlated with regional area and elevational range (Table 1a): these regional factors are predictors of the spatial climate variables (Table 1b).

\section{Richness patterns}


Habitat preference, distributional range and migratory behaviour categories are linked (see Appendix S2), with river species tending to be resident and endemic, and lake species to be migratory and widespread. The percentage of generalists increases with channel size in rivers and is greater in lake-dwelling, and in nonendemic, species (Fig. 2).

The BRT models account for at least $90 \%$ of the deviance for all but diadromous species, where $75 \%$ is explained. Clustering of relative influence values divides richness categories into those dominated by habitat specialist (cluster 1: total, river, resident and endemic species) and generalist species, which further divide into non-endemic, lake, potamodromous (cluster 2) and diadromous species (cluster 3) (see Appendix $\mathrm{S} 2$ ). $\mathrm{T}_{\max }$ is the most influential temperature variable (median $44 \%$, range $16-71 \%$ across richness categories) and the other temperature variables make similar contributions (medians 18\%), whereas rainfall variability was most important (medians 17, 21, 24, 34\% for mean, maximum, minimum and variability respectively). Across clusters, climate is less influential in diadromous species $(69,60$ and $45 \%$ respectively) and space/history is more important (Table 2). $T_{\max }$ is dominant for cluster $1, T_{\max }, R_{\min }, R_{\text {te }}$ and $R_{s p}$ are important for cluster 2 categories (Fig. 3) whereas area had the greatest influence on diadromous richness.

Temperature is more important than rainfall for the cluster 1 categories but of similar importance in the others.

The Atlantic has significantly fewer endemic and diadromous species than the Pacific and European realms but more species in the other richness categories (Table 2): climate-adjusted total richness in the Atlantic is $1.7 x$ that of the other realms. Across all richness categories, temperature variables are consistently stronger predictors (by univariate quadratic models) of richness than rainfall, and climatic effects are stronger in the Atlantic realm than in Europe (Fig. 4). In the Atlantic, all but the migratory species show significant declines with $\mathrm{T}_{\text {te }}$, consistent with a climatic variability effect (see Appendix S3), whereas in Europe there are small but significant positive correlations for total, river, lake and non-endemic richness categories.

The species richnesses of North American catostomids, centrarchids, cyprinids, ictalurids and percids decline from the south-east to the north-west (see Fig. 2 in Knouft \& Page, 2011). These taxa show similar rankings of coefficients for mean and seasonality in temperature and rainfall (see Appendix S3), declining in the sequence $T_{\text {mean }}, T_{\text {te }}, R_{\text {mean }}$ and $R_{\text {te }}$. Coefficients for salmonids, which have most species in the north-west, increase in the same sequence. The Atlantic families form two distinct clusters, of primary freshwater and saltwater tolerant families (see Appendix S3). In both realms temperature coefficients are larger than those for rainfall and the responses of European taxa tend to be weaker. 
The residuals from spatial autocorrelation analyses of richness and climate are concordant across richness categories for Atlantic (Kendall's $W=0.57, n=10, P<0.001)$ and European realms $(W=0.59, n=9$,

$246 P<0.001$ ) but show strong spatial structuring (Fig. 5), supporting the conclusion that effects other than climate 247 also affect richness patterns.

\section{Discussion}

\section{Climate patterns differ across realms}

251 Our regional climatic measures for North America are consistent with the grid square measures reported by 252 Badgley \& Fox (2000), the biggest discrepancy ( $T_{\max }$ showing a flatter latitudinal trend in their results) occurring because their data extend $15^{\circ}$ further south than ours.

The Pacific coastal margin is generally wet but the north-south trending mountain ranges create drier conditions to the east. Europe is strongly influenced by Atlantic Ocean weather patterns (Huntley \& Prentice, 2003) but lacks a sufficiently high north-south mountain range to generate a rain-shadow effect, such as that observed within the Mississippi Basin, i.e. the climate in North America is more diverse than in Europe, particularly at mid-latitudes where the Atlantic realm can be divided into arid western and mesic eastern zones (McAllister et al., 1986).

While previous analyses have treated correlations between climatic variables as spatially consistent, latitudinal climatic gradients are steeper and temperature and rainfall variables collinear in the Atlantic but orthogonal in Europe. This and other studies have ignored climate variable interaction effects. However, Arismendi et al. (2013) show increased seasonal synchrony between high temperatures and low flows in western North America, with potential effects on aquatic, particularly cold-water, species.

Richness is determined mainly by temperature

As expected, temperature accounted for more variation in richness than rainfall for single variable (and BRT) models, both across and within realms. Temperature should be a more important predictor of large-scale freshwater fish richness for at least three reasons. Firstly, temperature affects all aspects of existence whereas there is considerable variability in the sensitivity of fish species to variation in water supply e.g. small-

271 Secondly, the stronger latitudinal variation in temperature than in rainfall should favour a greater importance

272 for temperature. However, at the regional scale, where temperature variation is less marked, hydrological 273 variability has strong effects on fish assemblage structure and richness (Poff \& Ward, 1989). Finally, 
274 assuming that past environmental conditions influence richness patterns, temperature change since the last 275 glacial maximum (LGM) has varied strongly with latitude (Leprieur et al., 2011) whereas precipitation did not 276 (Araújo et al., 2008). However, the importance of temperature as a predictor varies with species ecology.

277 Ecology affects response to climate

278 Our results show clear effects of habitat, migration category and distributional range on the importance of 279 climate variables as richness predictors. The groupings of total, river and resident, and of lake, migratory and 280 non-endemic species, corresponding to predominantly habitat specialists and generalists, are expected.

281 Endemics cluster with river and resident species because of their largely non-glacial distributions (Griffiths, 282 2006; 2010). The strength of the climate-richness correlations is more a consequence of the steepness of the richness gradients than the importance of the variables e.g. larger climatic effects are found for residents than migrants simply because they show greater latitudinal variation in richness.

There is an extensive literature on the effects of thermal and hydrological factors on freshwater fish (for example, Poff \& Ward, 1989; Fang et al., 2004; Olden \& Kennard, 2010) and climate change is predicted to affect assemblage composition and richness (Buisson et al., 2010). Taylor \& Warren (2001) showed that species immigration and extinction rates, and therefore potentially richness, varies with channel size and flow variability. Discharge variability increases assemblage variability and reduces fish richness in French streams (Oberdorff et al., 2001). The increasing percentage of habitat specialists as channel size declines is expected: discharge variation, which varies with $\mathrm{R}_{\mathrm{te}}$, is greater in small drainage basins (Sabo et al., 2010) with their small channels. Inter-annual changes in richness correlate with hydrology in West African, and with temperature in French, rivers (Hugueny et al., 2010), a latitudinal difference similar to that found in terrestrial systems (Hawkins et al., 2003a).

Means, extremes and variability

Our results provide greater support for the physiological tolerance/climatic variability hypotheses than the 298 In general, temperature tends to be a better predictor of richness than energy measures (Storch, 2012). Annual means are unlikely to have direct effects on organisms, but are better regarded as surrogates for productivity. Globally, annual rainfall explains more variation in terrestrial NPP than annual temperature 301 (Schloss et al., 1999). There are clear latitudinal trends in terrestrial NPP (Schloss et al., 1999) but there have been few studies in freshwaters. Catchment productivity influences primary and hence secondary production in freshwaters via input of allochthonous material (Moss, 1998): however, primary production in lotic systems 
could be more important than allochthonous inputs because it is easier to assimilate and richer in nutrients (Thorp \& Delong, 2002). Terrestrial NPP is correlated with actual and potential evapotranspiration (AET, PET) (Rosenzweig, 1968; Churkina et al., 1999). Freshwater fish richness is correlated with annual AET in North America (Kerr \& Currie, 1999; Smith et al., 2010) while Zhao et al. (2006) found a PET effect in China. However, AET was not a significant predictor of global riverine fish richness whereas temperature and rainfall were (Oberdorff et al., 2011).

Climate extreme effects on richness (Addo-Bediako et al., 2000; Andrews \& O'Brien, 2000; Tognelli \& Kelt, 2004; Algar et al., 2009; Schuldt \& Assmann, 2009) have been reported more frequently than variability effects (Andrews \& O'Brien, 2000; Schuldt \& Assmann, 2009): whether this reflects reality or simply bias in what has been tested is not clear. Total richness increases with mean, maximum and minimum temperature in all realms (results not shown) and, except in Europe, declines with variability in temperature, as expected. However, the positive richness- $T_{\text {te }}$ correlation in Europe is inconsistent with the climate variability hypothesis. $T_{\max }$ can affect fish distributions by thermal and oxygen stress (Matthews, 1987; Rahel et al., 1996) while $T_{\min }$ potentially determines the northern limit of warm water species (Shuter \& Post, 1990). However, extremes tend to be correlated with variability (Ghalambor et al., 2006). T min declines more rapidly with latitude than $T_{\max }$ (see Appendix S1): latitudinal thermal tolerance in ectotherms increases with latitude and varies more with $T_{\min }$ than $T_{\max }$ (Sunday et al., 2011). The pervasive influence of heat above some thermal minimum on growth (the growing degree-day concept) attests to the important physiological effects of temperature (Neuheimer \& Taggart, 2007): fish richness in Michigan is correlated with degree-days (Latta et al., 2008) but other temperature measures were not investigated to compare predictive power. We found that total Atlantic richness increases with mean, maximum and minimum rainfall but there was no effect of temporal variability. Smith et al. (2010) showed that temperature extremes were important predictors of freshwater fish grid-square richness in North America, although $\mathrm{R}_{\text {mean }}$ had the strongest effect.

Historical and spatial variables affect species richness

Climate variables explain more richness variation in the Atlantic than in Europe, consistent with significant climatic influences on richness. However, differences in richness between realms suggest historical/spatial effects occur: Oberdorff et al. (1997) also report a 1.7x difference in richness between North American and European rivers. Our results suggest that history plays a relatively minor role in accounting for richness variation, in agreement with previous findings (Oberdorff et al., 2011; Tisseuil et al., 2012). Note however that despite showing large $T_{\max }$ effects the distributions of the dispersal-limited river, endemic and resident species 
are determined mainly by glaciation. Similarly, the richness $-T_{\text {te }}$ correlations, while inconsistent with a climate variability effect in Europe, are coincident with post-glacial recolonisation from the south-east in Europe and the south in North America. The area hypothesis, that the larger area of warmer, southern, habitats contributes to the latitudinal richness gradient, is supported in Europe but not in North America where area has declined to the south for at least 20 million years (Briggs, 1986).

The conclusion that historical/spatial variables are of limited importance in determining freshwater fish richness patterns assumes that there are no climate components in these variables. Elevational range had important effects on some richness categories in the Atlantic realm. However, the climate heterogeneity is generated by elevational heterogeneity which is a result of geological/historical processes. Our analyses used regional rather than grid square data but this larger spatial scale is likely to increase rather than reduce the contribution of climatic effects (Hortal et al., 2008; Field et al., 2009). In addition, the residuals in SAR analyses still show strong spatial structure, indicating that climate is insufficient to account for the spatial patterns. This is contrary to findings for birds and mammals (Badgley \& Fox, 2000; Hawkins et al., 2003b).

Like Knouft \& Page (2011), we found positive effects of temperature and rainfall on richness for six, species-rich, North American taxa and a negative temperature effect for cold-water salmonids. Primary freshwater families were more affected by temperature and mean rainfall than secondary/peripheral families. Knouft \& Page (2011) found that models incorporating elevation were the best, or very close to the best model $(\triangle \mathrm{AIC}<2)$ for all but salmonids. However, in our analyses models including elevation were the best in only 6/14 Atlantic and 1/8 European families (Griffiths, unpublished).

Leprieur et al. (2011) found that the extent of climate change since the LGM influenced the degree of difference in nested fish faunas (in Atlantic and European realms), consistent with extinction and colonisation effects. Others have also found evidence that climatic conditions since the LGM have affected species richness and endemism (for example, Jansson, 2003; Graham et al., 2006; Araújo et al., 2008; Jansson \& Davies, 2008; Oberdorff et al., 2011; Tedesco et al., 2012).

\section{Conclusions}

Climate, and in particular temperature, has a stronger effect on freshwater fish richness in North America than in Europe. This, in part, reflects the different patterns of correlation between the climate variables, with longer and stronger collinear gradients in North America. Richness categories with similar ecologies were similarly affected by climatic variables but spatial/historical variables were more important predictors of richness than climate for diadromous species. Total richness correlates more strongly with temperature maxima than annual 
364 means, suggesting that the richness gradient is driven more by physiological rather than energetic constraints 365 on species. This is consistent with an extensive literature on thermal and hydrological factors affecting fish 366 distributions and the considerable plasticity shown in growth rates in relation to food supply (Matthews, 1998). 367

368 Acknowledgements

369 Our thanks to Richard Field, Jason Knouft, Michael Dawson, Robert Whittaker and two anonymous referees 370 for comments that greatly improved the manuscript. 


\section{References}

Addo-Bediako, A., Chown, S.L. \& Gaston, K.J. (2000) Thermal tolerance, climatic variability and latitude. Proceedings of the Royal Society of London B, 267, 739-745.

Algar, A.C., Kharouba, H.M., Young, E.R. \& Kerr, J.T. (2009) Predicting the future of species diversity: macroecological theory, climate change, and direct tests of alternative forecasting methods. Ecography, 32, 22-33.

Andrews, P. \& O'Brien, E.M. (2000) Climate, vegetation, and predictable gradients in mammal species richness in southern Africa. Journal of Zoology, 251, 205-231.

Araújo, M.B., Nogués-Bravo, D., Diniz-Filho, J.A.F., Haywood, A.M., Valdes, P.J. \& Rahbek, C. (2008) Quaternary climate changes explain diversity among reptiles and amphibians. Ecography, 31, 8-15.

Arismendi, I., Safeeq, M., Johnson, S.L., Dunham, J.B. \& Haggerty, R. (2013) Increasing synchrony of high temperature and low flow in western North American streams: double trouble for coldwater biota? Hydrobiologia, 712, 61-70.

Badgley, C. \& Fox, D.L. (2000) Ecological biogeography of North American mammals: species density and ecological structure in relation to environmental gradients. Journal of Biogeography, 27, 1437-1467.

Briggs, J.C. (1986) Introduction to the zoogeography of North American fishes. The zoogeography of North American freshwater fishes (ed. by C.H. Hocutt and E.O. Wiley), pp. 1-16. J Wiley \& Sons, New York.

Buisson, L., Grenouillet, G., Casajus, N. \& Lek, S. (2010) Predicting the potential impacts of climate change on stream fish assemblages. American Fisheries Society Symposium, 73, 327-346.

Churkina, G., Running, S.W., Schloss, A.L. \& The participants of the Potsdam NPP model intercomparison (1999) Comparing global models of terrestrial net primary productivity (NPP): the importance of water availability Global Change Biology, 5, 46-55.

Clarke, A. \& Gaston, K.J. (2006) Climate, energy and diversity. Proceedings of the Royal Society B, 273, 2257-2266.

Currie, D.J., Mittelbach, G.G., Cornell, H.V., Field, R., Guégan, J.F., Hawkins, B.A., Kaufman, D.M., Kerr, J.T., Oberdorff, T., O'Brien, E. \& Turner, J.R.G. (2004) Predictions and tests of climate-based hypotheses of broad-scale variation in taxonomic richness. Ecology Letters, 7, 1121-1134.

Diniz-Filho, J.A.F., Bini, L.M. \& Hawkins, B.A. (2003) Spatial autocorrelation and red herrings in geographical ecology. Global Ecology \& Biogeography, 12, 53-64. 
Dormann, C.F., Elith, J., Bacher, S., Buchmann, C., Carl, G., Gabriel Carré, García Marquéz, J.R., Gruber, B., Lafourcade, B., Leitão, P.J., Münkemüller, T., McClean, C., Osborne, P.E., Reineking, B., Schröder, B., Skidmore, A.K., Zurell, D. \& Lautenbach, S. (2013) Collinearity: a review of methods to deal with it and a simulation study evaluating their performance. Ecography, 35, 27-46.

Dynesius, M. \& Jansson, R. (2000) Evolutionary consequences of changes in species geographical distributions driven by Milankovitch climate oscillations. Proceedings of the National Academy of Sciences, USA, 97, 9115-9120.

Elith, J., Leathwick, J.R. \& Hastie, T. (2008) A working guide to boosted regression trees. Journal of Animal Ecology, 77, 802-813.

Fang, X., Stefan, H.G., Eaton, J.G., McCormick, J.H. \& Alam, S.R. (2004) Simulation of thermal/dissolved oxygen habitat for fishes in lakes under different climate scenarios Part 1. Cool-water fish in the contiguous US. Ecological Modelling, 172, 13-37.

Ferguson, S.H. \& Messier, F. (1996) Ecological implications of a latitudinal gradient in inter-annual climatic variability: a test using fractal and chaos theories. Ecography, 19, 382-392.

Field, R., Hawkins, B.A., Cornell, H.V., Currie, D.J., Diniz-Filho, J.A.F., Guégan, J.-F., Kaufman, D.M., Kerr, J.T., Mittelbach, G.G., Oberdorff, T., O'Brien, E.M. \& Turner, J.R.G. (2009) Spatial species-richness gradients across scales: a meta-analysis. Journal of Biogeography, 36, 132-147.

Filipe, A.F., Araújo, M.B., Doadrio, I., Angermeier, P.L. \& Collares-Pereira, M.J. (2009) Biogeography of Iberian freshwater fishes revisited: the roles of historical versus contemporary constraints. Journal of Biogeography, 36, 2096-2110.

Fu, C., Wu, J., Wang, X., Lei, C. \& Chen, J. (2004) Patterns of diversity, altitudinal range and body size among freshwater fishes in the Yangtze River basin, China. Global Ecology and Biogeography, 13, $543-552$.

Gaston, K.J. (2003) The structure and dynamics of geographic ranges. Oxford University Press, Oxford.

Ghalambor, C.K., Huey, R.B., Martin, P.R., Tewksbury, J.J. \& Wang, G. (2006) Are mountain passes higher in the tropics? Janzen's hypothesis revisited. Integrative and Comparative Biology, 46, 5-17.

Graham, C.H., Moritz, C. \& Williams, S.E. (2006) Habitat history improves prediction of biodiversity in rainforest fauna. Proceedings of the National Academy of Sciences, U. S. A., 103, 632-636.

Gregory, K.J. \& Walling, D.E. (1973) Drainage basin form and process: a geomorphological approach. Edward Arnold, London. 
Griffiths, D. (2006) Pattern and process in the ecological biogeography of European freshwater fish. Journal of Animal Ecology, 75, 734-751.

Griffiths, D. (2010) Pattern and process in the distribution of North American freshwater fish. Biological Journal of the Linnean Society, 100, 46-61.

Hawkins, B.A., Field, R., Cornell, H.V., Currie, D.J., Guégan, J.-F., Kaufman, D.M., Kerr, J.T., Mittelbach, G.G., Oberdorff, T., O'Brien, E.M., Porter, E.E. \& Turner, J.R.G. (2003a) Energy, water, and broadscale geographic patterns of species richness. Ecology, 84, 3105-3117.

Hawkins, B.A., Porter, E.E. \& Diniz-Filho, J.A.F. (2003b) Productivity and history as predictors of the latitudinal diversity gradient of terrestrial birds. Ecology, 84, 1608-1623.

Hijmans, R.J., Phillips, S., Leathwick, J. \& Elith, J. (2013) dismo: Species distribution modeling. Available at: R package version 0.8-5 http://CRAN.R-project.org/package=dismo (accessed 20/2/13

Hortal, J., Rodríguez, J., Nieto-Díaz, M. \& Lobo, J.M. (2008) Regional and environmental effects on the species richness of mammal assemblages. Journal of Biogeography, 35, 1202-1214.

Hugueny, B., Oberdorff, T. \& Tedesco, P.A. (2010) Community ecology of river fishes: a large-scale perspective. American Fisheries Society Symposium, 73, 29-62.

Huntley, B. \& Prentice, I.C. (2003) Holocene vegetation and climates of Europe. Global climates since the last glacial maximum (ed. by H.E. Wright, J.E. Kutzbach, T. Webb, W.F. Ruddiman, F.A. Street-Perrott and P.J. Bartlein), pp. 136-168. University of Minnesota Press, Minneapolis.

Illies, J. (1978) Limnofauna Europaea. Gustav Fischer Verlag, Stuttgart.

Jansson, R. (2003) Global patterns in endemism explained by past climatic change. Proceedings of the Royal Society of London B, 270, 583-590.

Jansson, R. \& Davies, T.J. (2008) Global variation in diversification rates of flowering plants: energy vs. climate change. Ecology Letters, 11, 173-183.

Jetz, W. \& Rahbek, C. (2002) Geographic range size and determinants of avian species richness. Science, 297, 1548-1551.

Jocque, M., Field, R., Brendonck, L. \& de Meester, L. (2010) Climatic control of dispersal-ecological specialization trade-offs: a metacommunity process at the heart of the latitudinal diversity gradient? Global Ecology and Biogeography, 19, 244-257.

Jones, J.A.A. (1997) Global hydrology: processes, resources and environmental management. Addison Wesley Longman Ltd., Harlow. 
Kerr, J.T. \& Currie, D.J. (1999) The relative importance of evolutionary and environmental controls on broadscale patterns of species richness in North America. Ecoscience, 6, 329-337.

Knouft, J.H. \& Page, L.M. (2011) Assessment of the relationships of geographic variation in species richness to climate and landscape variables within and among lineages of North American freshwater fishes. Journal of Biogeography, 38, 2259-2269.

Kratz, T.K., Webster, K.E., Bowser, C.J., Magnuson, J.J. \& Benson, B.J. (1997) The influence of landscape position on lakes in northern Wisconsin. Freshwater Biology, 37, 209-217.

Latta, W.C., Breck, J.E. \& Marshall Duchon, E.R. (2008) Species-area and latitudinal patterns for Michigan fishes. American Midland Naturalist, 159, 349-363.

Leprieur, F., Tedesco, P.A., Hugueny, B., Beauchard, O., Dürr, H.H., Brosse, S. \& Oberdorff, T. (2011) Partitioning global patterns of freshwater fish beta diversity reveals contrasting signatures of past climate changes. Ecology Letters, 14, 325-334.

Lieth, H. (1975) Modelling the primary productivity of the world. Primary productivity of the biosphere (ed. by H. Lieth and R.H. Whittaker), pp. 237-283. Springer-Verlag, New York.

Livingstone, D.A., Rowland, M. \& Bailey, P.E. (1982) On the size of African riverine fish faunas. American Zoologist, 22, 361-369.

Matthews, W.J. (1987) Physicochemical tolerance and selectivity of stream fishes as related to their geographic ranges and local distributions. Community and evolutionary ecology of North American stream fishes (ed. by W.J. Matthews and D.C. Heins), pp. 111-120. University of Oklahoma Press, Norman, Oklahoma.

Matthews, W.J. (1998) Patterns in freshwater fish ecology. Chapman \& Hall, New York.

McAllister, D.E., Platania, S.P., Schueler, F.W., Baldwin, M.E. \& Lee, D.S. (1986) Ichthyofaunal patterns on a geographic grid. The zoogeography of North American freshwater fishes (ed. by C.H. Hocutt and E.O. Wiley), pp. 17-51. J Wiley \& Sons, New York.

Mittelbach, G.G., Schemske, D.W., Cornell, H.V., Allen, A.P., Brown, J.M., Bush, M.B., Harrison, S.P., Hurlbert, A.H., Knowlton, N., Lessios, H.A., McCain, C.M., McCune, A.R., McDade, L.A., McPeek, M.A., Near, T.J., Price, T.D., Ricklefs, R.E., Roy, K., Sax, D.F., Schluter, D., Sobel, J.M. \& Turelli, M. (2007) Evolution and the latitudinal diversity gradient: speciation, extinction and biogeography. Ecology Letters, 10, 315-331.

Moss, B. (1998) Ecology of fresh waters, 3rd edn. Blackwell Science, Oxford. 
Moyle, P.B. \& Herbold, B. (1987) Life-history patterns and community structure in stream fishes of western North America: comparisons with eastern North America and Europe. Community and evolutionary ecology of North American stream fishes (ed. by W.J. Matthews and D.C. Heins), pp. 25-32. University of Oklahoma Press, Norman, Oklahoma.

Neuheimer, A.B. \& Taggart, C.T. (2007) The growing degree-day and fish size-at-age: the overlooked metric. Canadian Journal of Fisheries and Aquatic Sciences, 64, 375-385.

Oberdorff, T., Guégan, J.F. \& Hugueny, B. (1995) Global scale patterns of fish species richness in rivers. Ecography, 18, 345-352.

Oberdorff, T., Hugueny, B. \& Guégan, J.F. (1997) Is there an influence of historical events on contemporary fish species richness in rivers? Comparisons between western Europe and North America. Journal of Biogeography, 24, 461-467.

Oberdorff, T., Lek, S. \& Guégan, J.F. (1999) Patterns of endemism in riverine fish of the northern hemisphere. Ecology Letters, 2, 75-81.

Oberdorff, T., Hugueny, B. \& Vigneron, T. (2001) Is assemblage variability related to environmental variability? An answer for riverine fish. Oikos, 93, 419-428.

Oberdorff, T., Tedesco, P.A., Hugueny, B., Leprieur, F., Beauchard, O., Brosse, S. \& Dürr, H.H. (2011) Global and regional patterns in riverine fish species richness: a review. International Journal of Ecology, 2011, 12.

Olden, J.D. \& Kennard, M.J. (2010) Intercontinental comparison of fish life history strategies along a gradient of hydrologic variability. American Fisheries Society Symposium, 73, 83-107.

Page, L.M. \& Burr, B.M. (1991) A field guide to freshwater fishes of North America north of Mexico. Houghton Mifflin Company, Boston.

Poff, N.L. \& Ward, J.V. (1989) Implications of streamflow variability and predictability for lotic community structure: a regional analysis of streamflow patterns. Canadian Journal of Fisheries and Aquatic Sciences, 46, 1805-1818.

R Core Development Team (2012) R: A Language and Environment for Statistical Computing. In. R Foundation for Statistical Computing, Vienna, Austria.

Rahel, F.J., Keleher, C.J. \& Anderson, J.L. (1996) Potential habitat loss and population fragmentation for cold water fish in the North Platte River drainage of the Rocky Mountains: Response to climate warming. Limnology and Oceanography, 41, 1116-1123. 
Rangel, T.F., Diniz-Filho, J.A.F. \& Bini, L.M. (2010) SAM: a comprehensive application for Spatial Analysis in Macroecology. Ecography, 33, 46-50.

Rosenzweig, M.L. (1968) Net primary productivity of terrestrial communities: predictions from climatological data. American Naturalist, 102, 67-74.

Rosenzweig, M.L. (1995) Species diversity in space and time. Cambridge University Press, Cambridge.

Sabo, J.L., Finlay, J.C., Kennedy, T. \& Post, D.M. (2010) The role of discharge variation in scaling of drainage area and food chain length in rivers. Science, 330, 965-967.

Schloss, A.L., Kicklighter, D.W., Kaduk, J., Wittenberg, U. \& The Participants of the Potsdam NPP Model Intercomparison (1999) Comparing global models of terrestrial net primary productivity (NPP): comparison of NPP to climate and the Normalized Difference Vegetation Index (NDVI. Global Change Biology, 5 (Suppl. 1), 16-25.

Schuldt, A. \& Assmann, T. (2009) Environmental and historical effects on richness and endemism patterns of carabid beetles in the western Palaearctic. Ecography, 32, 705-714.

Shuter, B.J. \& Post, J.R. (1990) Climate, population variability and the zoogeography of temperate fishes. Transactions of the American Fisheries Society, 119, 314-336.

Smith, G.R., Badgley, C., Eiting, T.P. \& Larson, P.S. (2010) Species diversity gradients in relation to geological history in North American freshwater fishes. Evolutionary Ecology Research, 12, 693-726.

Southwood, T.R.E. (1977) Habitat, the templet for ecological strategies? Journal of Animal Ecology, 46, 337365.

Stevens, G.C. (1989) The latitudinal gradient in geographical range: how so many species coexist in the tropics. American Naturalist, 133, 240-256.

Storch, D. (2012) Biodiversity and its energetic and thermal controls. Metabolic ecology: a scaling approach (ed. by R.M. Sibly, J.H. Brown and A. Kodric-Brown), pp. 120-131. John Wiley \& Sons, Chichester.

Sunday, J.M., Bates, A.E. \& Dulvy, N.K. (2011) Global analysis of thermal tolerance and latitude in ectotherms. Proceedings of the Royal Society B, 278, 1823-30.

Svenning, J.C. \& Skov, H. (2005) The relative roles of environment and history as controls of tree species composition and richness in Europe. Journal of Biogeography, 32, 1019-1033.

Tarroso, P. \& Rebelo, H. (2010) E-Clic - easy climate data converter. Ecography, 33, 617-620.

Taylor, C.M. \& Warren, M.L. (2001) Dynamics in species composition of stream fish assemblages: environmental variability and nested subsets. Ecology, 82, 2320-2330. 
550 Tedesco, P.A., Oberdorff, T., Lasso, C.A., Zapata, M. \& Hugueny, B. (2005) Evidence of history in explaining 551 diversity patterns in tropical riverine fish. Journal of Biogeography, 32, 1899-1907.

Tedesco, P.A., Leprieur, F., Hugueny, B., Brosse, S., Dürr, H.H., Beauchard, O., Busson, F. \& Oberdorff, T. (2012) Patterns and processes of global riverine fish endemism. Global Ecology and Biogeography, 21, 977-987.

Thorp, J.H. \& Delong, M.D. (2002) Dominance of autochthonous autotrophic carbon in food webs of heterotrophic rivers. Oikos, 96, 543-550.

Tisseuil, C., Cornu, J.-F., Beauchard, O., Brosse, S., Darwall, W., Holland, R., Hugueny, B., Tedesco, P.A. \& Oberdorff, T. (2012) Global diversity patterns and cross-taxa convergence in freshwater systems. Journal of Animal Ecology, 82, 365-376.

Tognelli, M.F. \& Kelt, D.A. (2004) Analysis of determinants of mammalian species richness in South America using spatial autoregressive models. Ecography, 27, 427-436.

Vásquez, D.P. \& Stevens, R.D. (2004) The latitudinal gradient in niche breadth: concepts and evidence. American Naturalist, 164, E1-E19.

Willig, M.R., Kaufman, D.M. \& Stevens, R.D. (2003) Latitudinal gradients of biodiversity: pattern, process, scale, and synthesis. Annual Review of Ecology, Evolution, and Systematics, 34, 273-309.

Willis, K.J., Kleczkowski, A., New, M. \& Whittaker, R.J. (2007) Testing the impact of climate variability on European plant diversity: 320000 years of water-energy dynamics and its long-term influence on plant taxonomic richness. Ecology Letters, 10, 673-679.

Xenopoulos, M.A., Lodge, D.M., Alcamo, J., Märker, M., Schulze, K. \& van Vuurens, D.P. (2005) Scenarios of freshwater fish extinctions from climate change and water withdrawal. Global Change Biology, 11, 1557-1564.

Zhao, S., Fang, J., Peng, C., Tang, Z. \& Piao, S. (2006) Patterns of fish species richness in China's lakes. Global Ecology and Biogeography, 15, 386-394. 


\section{Supporting Information}

577 Additional Supporting Information may be found in the online version of this article:

578 Appendix S1 Climate correlations.

579 Appendix S2 Climate and realm effects.

580 Appendix S3 Climate variation effects.

581

582 As a service to our authors and readers, this journal provides supporting information supplied by the authors.

583 Such materials are peer-reviewed and may be re-organized for online delivery, but are not copy-edited or

584 typeset. Technical support issues arising from supporting information (other than missing files) should be 585 addressed to the authors. 
587 Table 1. (a) Pearson correlation coefficients (boldface values $P<0.05)$ between regional area $\left(\mathrm{km}^{2}\right)$,

588 elevational range $(\mathrm{m})$, latitude $\left({ }^{\circ} \mathrm{N}\right)$ and longitude $\left({ }^{\circ} \mathrm{W}\right)$ and the climate variables and $(\mathrm{b})$ standardised

589 regression coefficients of regional spatial variables predicting the spatial climatic variables for the Atlantic and 590 European realms.

591

$592 \quad(a)$

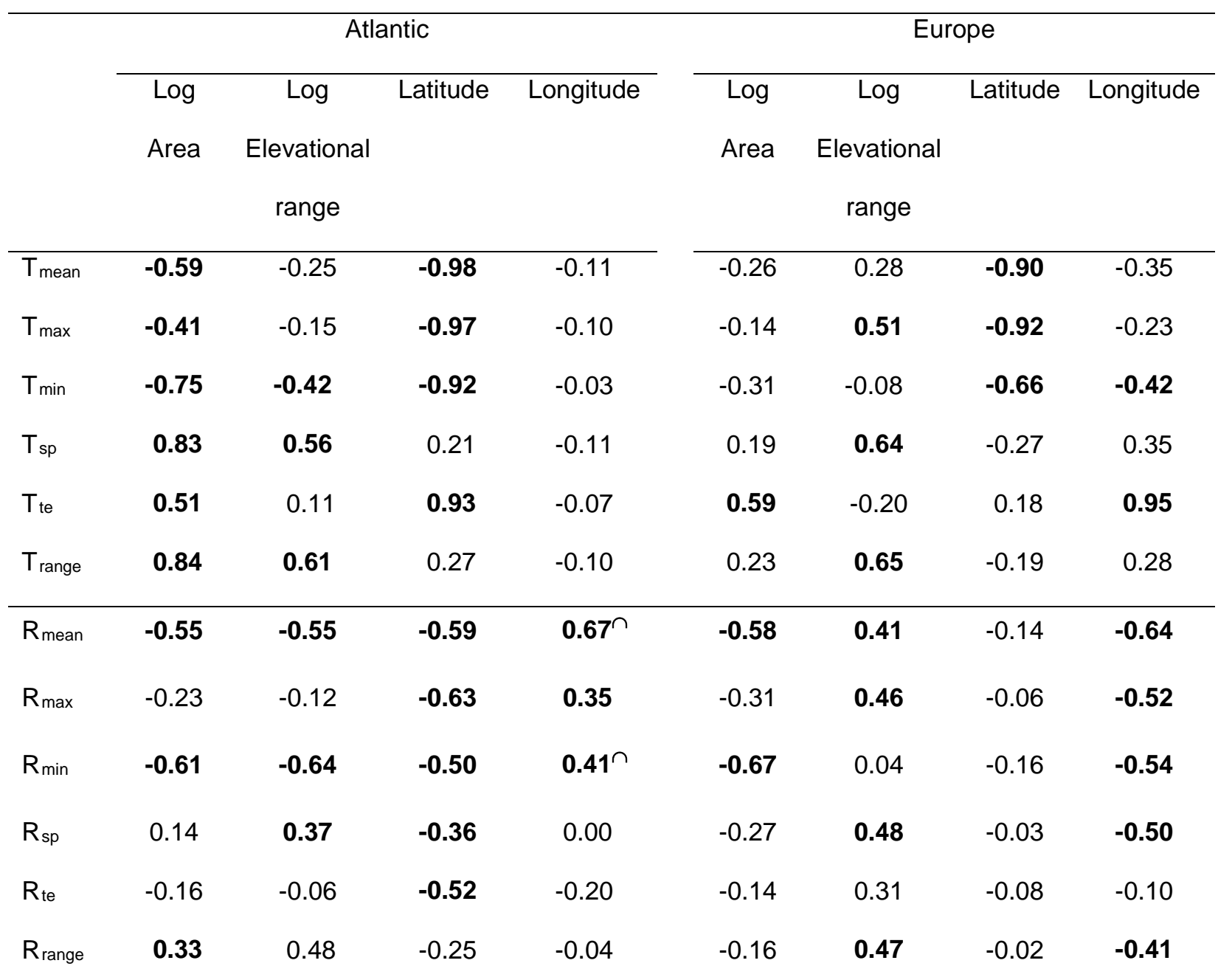

\begin{tabular}{lcccc}
\hline & \multicolumn{2}{c}{ LogT $_{s p}$} & \multicolumn{2}{c}{$\underline{\text { LogR }}$ sp } \\
& Atlantic & Europe & Atlantic & Europe \\
\hline Log Area & $0.78^{\star \star \star}$ & $0.38^{\star}$ & -0.13 & -0.16 \\
Log Elevational range & 0.09 & $0.74^{\star \star \star}$ & $0.45^{\star}$ & $0.44^{\star}$ \\
\hline
\end{tabular}




\begin{tabular}{lllll}
\hline$R^{2}$ & 0.68 & 0.55 & 0.15 & 0.18
\end{tabular}

$596 \quad$ Coefficient $=0 ; P^{*}<0.05,{ }^{\star *}<0.01,{ }^{* \star *}<0.001$ 
597 Table 2. (a) Relative influence values (\%), grouped as climatic, historical and spatial, on (log) species richness 598 for the different richness categories. Climatic = Temperature + Rainfall: component values are shown in Fig. 599 2. The final column shows post hoc tests for realm differences using the BRT partial dependence values, of 600 the hypothesis Atlantic richness (a) differs from that in Pacific (p) and European(e) realms. (b) Least square 601 means of total species richness by realm, from partial dependence values.

$602 \quad(a)$

\begin{tabular}{lrrrrrc}
\hline Richness category & Temperature & Rainfall & Climatic & Historical & Spatial & a<>p,e \\
\hline Total & 46.0 & 24.0 & 70.1 & 4.3 & 25.6 & $* \star \star$ \\
\hline River & 46.7 & 24.5 & 71.2 & 4.1 & 24.7 & $* \star \star$ \\
Lake & 28.9 & 31.3 & 60.2 & 4.8 & 35.0 & $* \star \star$ \\
\hline Non-endemic & 33.6 & 31.7 & 65.3 & 7.3 & 27.4 & $* \star \star$ \\
Endemic & 45.4 & 20.8 & 66.3 & 3.3 & 30.4 & $*$ \\
\hline Diadromous & 22.8 & 22.0 & 44.8 & 12.2 & 43.0 & $* * \star$ \\
Potamodromous & 28.9 & 23.5 & 52.4 & 3.4 & 44.2 & \\
Resident & 48.7 & 21.4 & 70.1 & 8.4 & 21.5 & $* \star \star$
\end{tabular}

${ }^{\star} P<0.05,{ }^{\star \star} P<0.01,{ }^{\star \star \star} P<0.001$

604

605

(b)

\begin{tabular}{lrr}
\hline Realm & Mean \pm S.e. & $n$ \\
\hline Atlantic & $1.915 \pm 0.042$ & 39 \\
Pacific & $1.745 \pm 0.092$ & 8 \\
Europe & $1.650 \pm 0.053$ & 24 \\
\hline
\end{tabular}


$607 \quad$ Figure legends

608 Fig. 1. Mean annual regional (a) temperatures $\left({ }^{\circ} \mathrm{C}\right)$ and (b) rainfall $\left(\mathrm{cm} \mathrm{y}^{-1}\right)$ as a function of latitude for Atlantic 609 (circles), Pacific (crosses) and European (triangles) realms.

610

611 Fig. 2. The percentage (mean $\pm 95 \% \mathrm{CL}$ ) of generalists (species found in both rivers and lakes) varies with (a) 612 channel size in Atlantic (circles) and Pacific (crosses) realms and (b) migration category in lakes (circles) and 613 rivers (triangles), and for endemics (square) and non-endemics (diamond). Channel size information was from 614 Page \& Burr (1991): this information was not available for European species but $85.3 \pm 5.8 \%$ of species found 615 in lakes there were generalists.

616

617 Fig. 3. Relative influence values of environmental variables from BRT for (a) total, riverine, endemic and 618 resident (b) generalist, non-endemic and potamodromous and (c) lacustrine and diadromous richness 619 categories. Predictor variables are grouped into temperature, rainfall, historical (realm \& glaciation) and spatial 620 (area, elevational range, $T_{s p}, R_{s p}$ ) categories.

621

622 Fig. 4. Mean $R^{2}$ (from univariate quadratic models) \pm 1 s.e. across nine richness categories for temperature 623 and rainfall variables (a) across all realms and (b) in Atlantic (circles) and European (diamonds) realms. 624

625 Fig. 5. Correlograms of species richness (circles) and residuals (triangles) for (a) Atlantic and (b) Europe. All 626 the temperature and rainfall variables were used as predictors. The error bars are the $95 \%$ confidence 627 intervals of the mean Moran I coefficients, averaged across richness categories. 

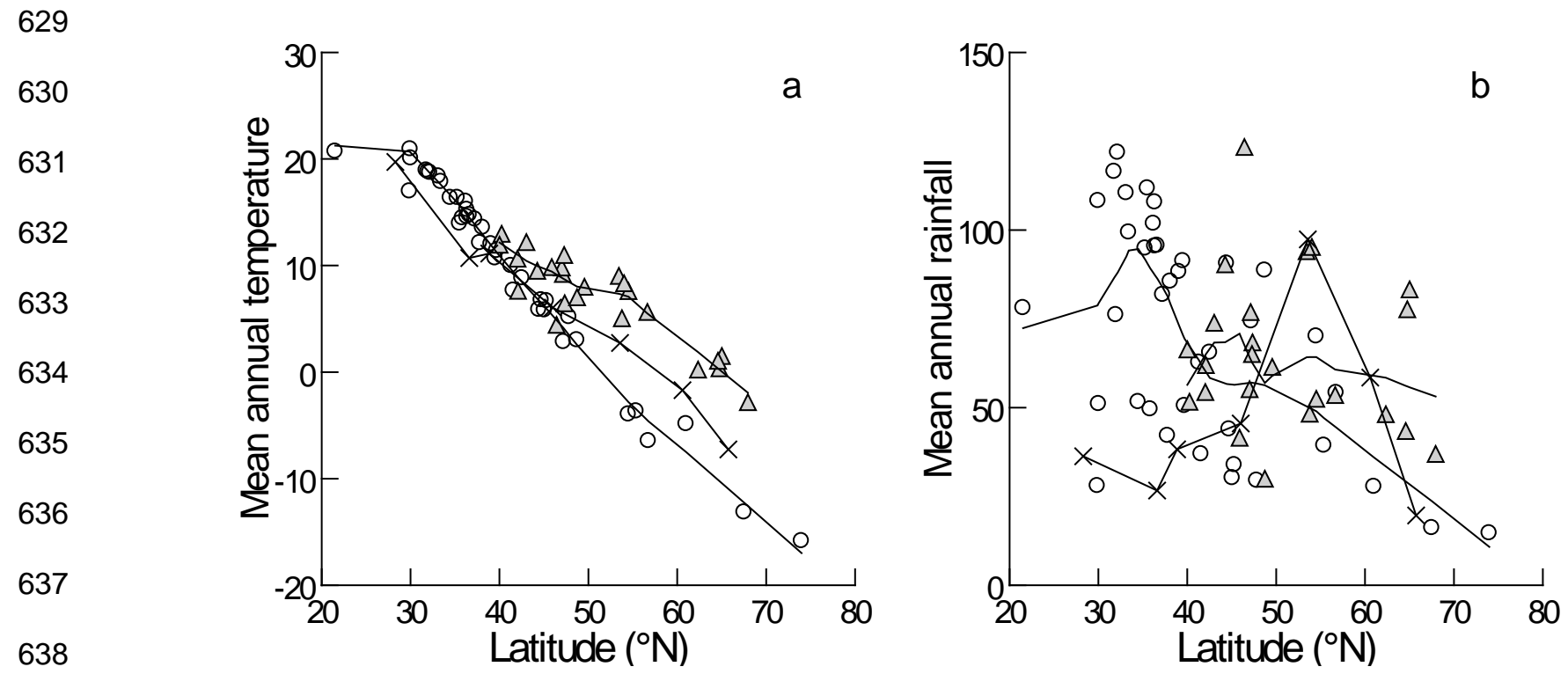

639

640 Fig. 1. Mean annual regional (a) temperatures $\left({ }^{\circ} \mathrm{C}\right)$ and (b) rainfall $\left(\mathrm{cm} \mathrm{y}^{-1}\right)$ as a function of latitude for Atlantic 641 (circles), Pacific (crosses) and European (triangles) realms. 

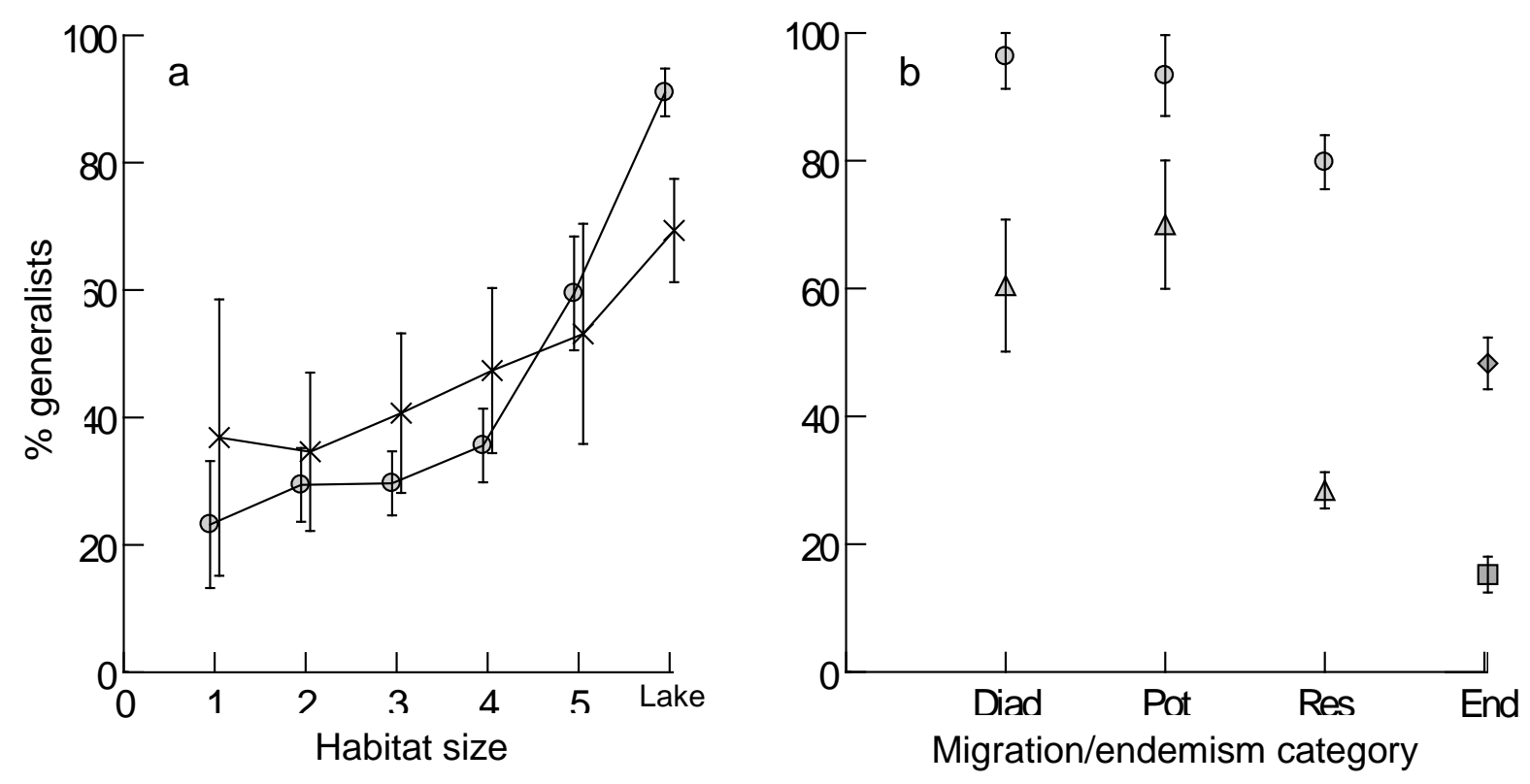

660 Fig. 2. The percentage (mean $\pm 95 \% \mathrm{Cl}$ ) of generalists (species found in both rivers and lakes) varies with (a) 661 channel size in Atlantic (circles) and Pacific (crosses) realms and (b) migration category in lakes (circles) and 662 rivers (triangles), and for endemics (square) and non-endemics (diamond). Channel size information was from 663 Page \& Burr (1991): this information was not available for European species but $85.3 \pm 5.8 \%$ of species found 664 in lakes there were generalists. 

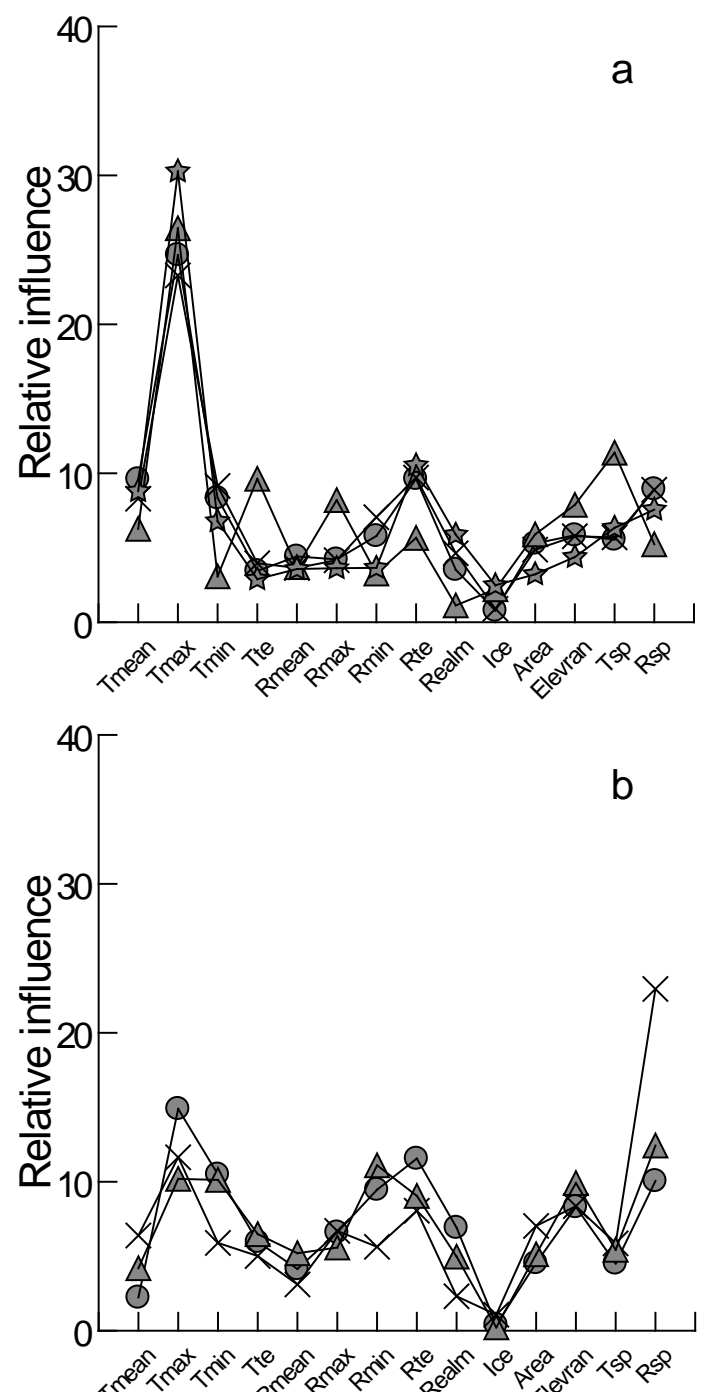

693 Fig. 3. Relative influence values of environmental variables from BRT for (a) total, river, endemic and resident

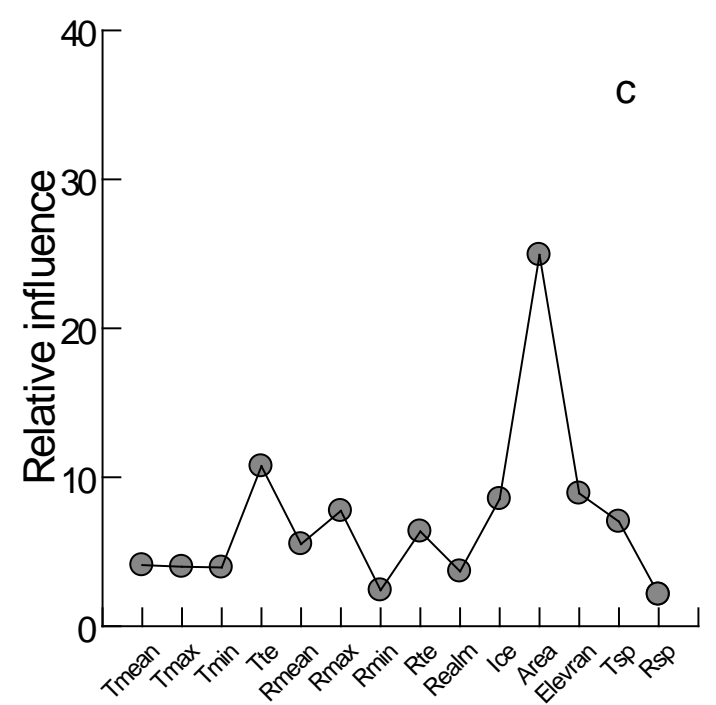

- Diadromous 
695 ordered as temperature, rainfall, historical (realm \& glaciation) and spatial (area, elevational range, $T_{\mathrm{sp}}, \mathrm{R}_{\mathrm{sp}}$ ) 696 categories.

697 

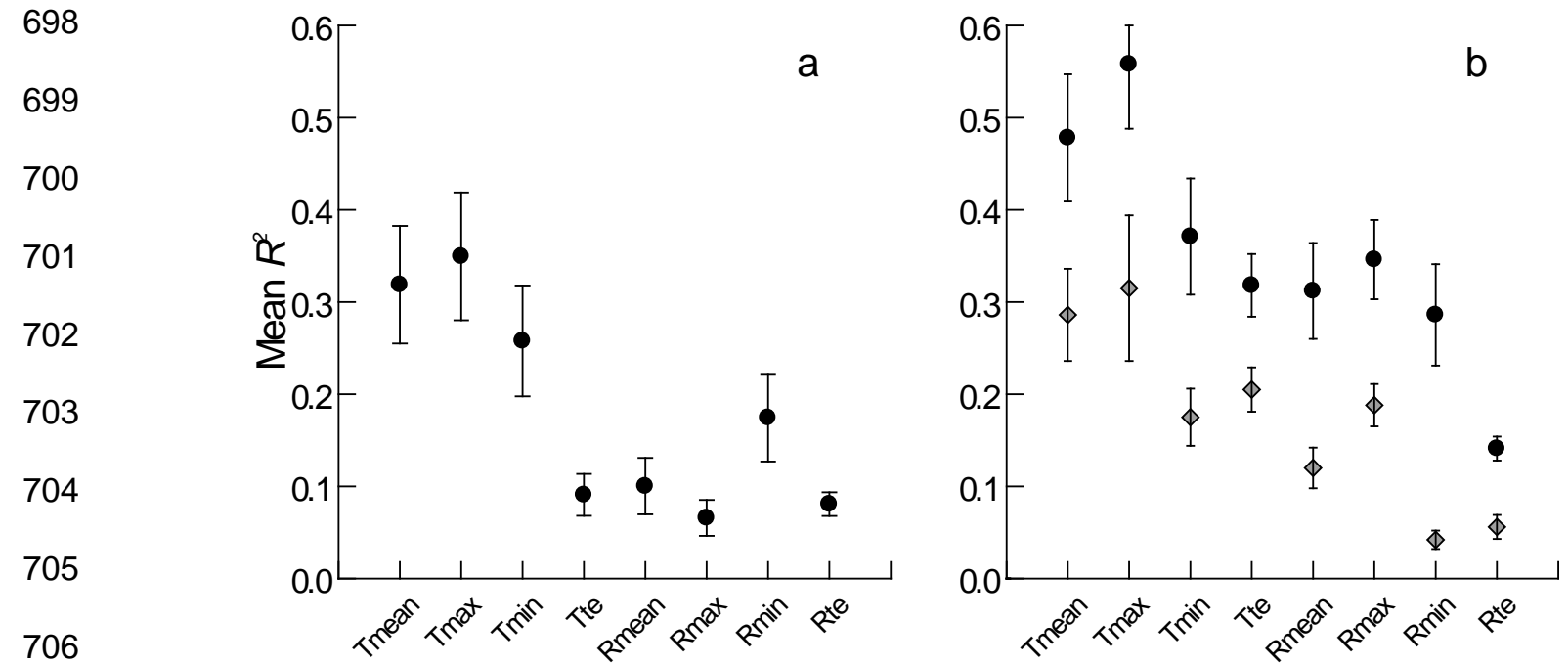

707

Fig. 4. Mean $R^{2}$ (from univariate quadratic models) \pm 1 SE across eight richness categories for temperature 708 and rainfall variables (a) across all realms and (b) in Atlantic (circles) and European (diamonds) realms. 

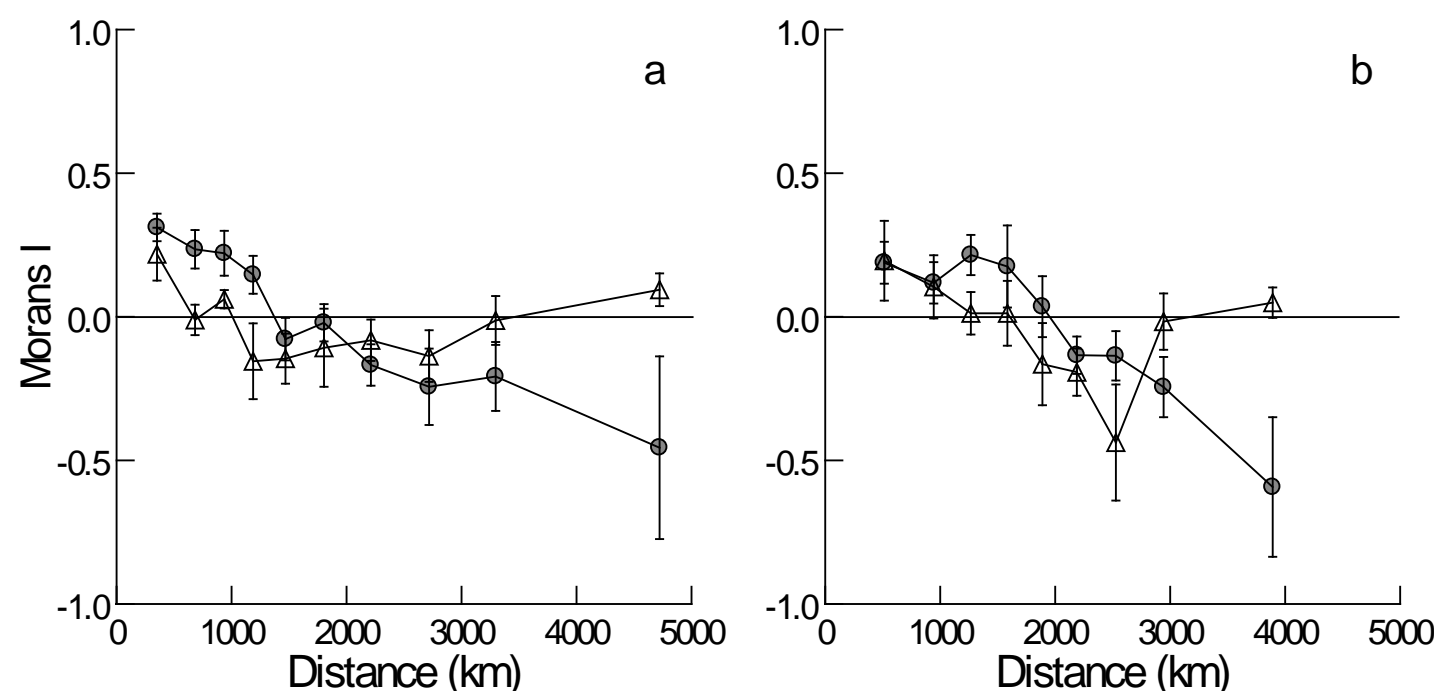

718

719 Fig. 5. Correlograms of species richness (circles) and residuals (triangles) for (a) Atlantic and (b) Europe. All 720 the temperature and rainfall variables were used as predictors. The error bars are the $95 \%$ confidence 721 intervals of the mean Moran I coefficients, averaged across richness categories. 


\section{Biosketches}

723 David Griffiths is interested in fish biogeography, the structure and functioning of aquatic systems at all 724 scales and the effects of iron deposition in stream systems.

725 Chris McGonigle is interested in the community structure of marine benthic ecosystems, in particular the role 726 of physical processes in driving patterns of spatial and temporal variation.

Rory Quinn is interested in spatial mapping and the links between geological processes and biogeography. 728

Author contributions: D.G. conceived the ideas; D.G., C.M. and R.Q. collected and analysed the data; and 730 D.G. led the writing.

Editor: Michael Dawson 